\title{
Semantic And Idiomatic Features Of Interpreting Phraseological Units From English Into Uzbek
}

\author{
Abidova Rokhatoy, Baydjanova Iroda, Madraimov Jafar, Matmurodov Khojimurod, Marimbaeva \\ Laylo \\ Urgench State University, Urgench, Uzbekistan. \\ E-mail: r.abidova@bk.ru
}

Article History: Received:11 January 2021; Accepted: 27 February 2021; Published online: 5 April 2021

Abstract: The issue focused on the linguistic distinctiveness of Phraseological units, their grouping, the difficulties in the interpretation of phraseological units, techniques of their interpretation from one language into another.

\begin{abstract}
Keywords: categorization, phraseological, interpretation difficulties, lexicon, interpretation methods, idioms
\end{abstract}
\section{INTRODUCTION}

Today English became as an international language. In all probability no one today who does not know English. Nowadays, it is studied in all countries. But English is gradually changing, just like any other language: new idioms, proverbs and sayings appear in it. So it is important to know not only its classical version, but also conversational, because otherwise you cannot understand a native speaker.

In accordance with article we would like to look at such linguistic occurrence as phraseological units and contrast their interpretation in Uzbek and English languages.

As a special sphere of activity, interpretation occupies an important place in the history of human development. It is through rendered literature that the peoples of the world get to know the history, customs and culture of each other and have the opportunity to read the great works of the world's authors in their native vernacular. As you know, interpretation is a rather time-consuming and complicated process that poses certain problems and challenges to the translator. The problems faced by the translator affect the process of interpretation, significantly slowing down its course.

\section{MATERIALS AND METHODS}

One of such problems creating additional difficulties for the translator is the problem of interpretation of English phraseological combinations into Uzbek language.

In general, phraseological expressions are a very original modes of expression in the language of the rich popular imagination. The diversity of the form and content of phraseological units, as well as their wide distribution in the language has attracted the attention of researchers to them. Thus, over time, phraseology stands out as a special section of lexicology as one of the parts of linguistics.

The study of the internal structure of meaning and the external structure of phraseological units, their place in individual languages, interpretation possibilities, national and universal meaning, the peculiarities of their use and areas of application have not lost their relevance even today and represent a scientific and practical interest.

It is acknowledged that, phraseological units, or related, stable word combinations, sometimes even whole sentences, have either fully or partially figurative meaning. The main feature of phraseological units, according to many modern researchers, is the discrepancy between the content plan and the expression plan, which determines the specificity of the phraseological unit and gives depth and flexibility to its meaning. These possibilities are apparently rooted in the very nature of the phraseological unit, a closed micro-context in which not only formal links between the plan of expression and the plan of content of such a sign are realized, but also associative-semantic ones, and not necessarily logically deducible from the micro-context itself. It is this inescapability that allows phraseology to denote the most complex phenomena and relations of reality in a capacious and expressive form. The phraseological expressions play an important role in communication and give different shades to the way of expression: they can make a statement (text) more emotional, give it expressiveness, direct the aesthetic perception in a certain way, provide certain cultural associations, etc. Very often phraseological expressions serve as a kind of code for recognizing the status of the text (the interlocutor, the topic of the statement, the relationship between the participants in communication, etc.).

As previously indicated, English language learning is also widespread in our country. A good knowledge of the language, including English, is impossible without knowledge of its phraseology. Knowledge of phraseology makes it extremely easy to read both publicist and fiction literature.

We should note that not only inexperienced translators can make mistakes when interpreting English idioms, but experienced translators can also face great difficulties. Linguists offer several different methods to overcome interpretation problems. Proceeding from this, the main purpose of our article is to study the already 
known different methods of interpretation of English phrases into Uzbek language, consideration of the problems arising in this case and methods of their elimination.

Certain difficulties arise when interpreting words or phrases with different context. Often, two words with absolutely dissimilar meanings enter into a semantic relationship within one phrase in order to express the same meaning. To eliminate problems of this type, research work was carried out, the result of which can be considered the compilation of a collection of phraseological expressions. The words included in this collection are called "Set expression" in English, and phraseological dictionaries or phraseological combinations in the Uzbek language. The publication of such collections makes the interpretation process a little easier.

The main reasons for the incorrect interpretation of phraseological expressions can be their incorrect selection from the context, and the inability to distinguish them from free word combinations. Another reason can be the translator's misunderstanding of the meaning of these phrases, which leads to a distortion of the text. Therefore, in order to correctly render phraseological units, the translator must first of all isolate the phraseological combinations from the context, correctly understand them and correctly express the idea behind the phrase without distorting its meaning. The interpreter must have a good knowledge of the life of the people of the source language and its national characteristics. When interpreting idioms, you should be able to correctly use the phraseological dictionary, pay attention to the linguistic and stylistic features of the text.

\section{DISCUSSION}

Speaking about the interpretation of phraseological expressions, first of all, we should pay attention to two important points: a) it is necessary to fully understand the phraseological expressions to be rendered; b) the understood phraseological expression in the native language by adequate language means. The interpretation process consisting of these two moments analyzes the English phraseological expression from the semantic, stylistic and grammatical points of view. It determines both the lexical meaning and the stylistic features of the combination, as well as its grammatical meaning and objectives. All this complies with the norms of the native language, resulting in the selection of an appropriate expression from the native language. Thus, the entire interpretation process is realized through comparisons and comparisons.

The phraseological expressions in foreign languages, particular in English, have a specific character, so their literal interpretation into Uzbek does not always reflect the expression, connotation, the bright meaning that the idiom had in the source language. Differences in the picture of the world, culture, world perception of different peoples make it impossible in some cases to interchange phraseological units in interpretation. English phraseological units when rendered into Uzbek sometimes completely change their meaning. Therefore, the study of methods of interpretation of idioms is still relevant.

It is paramount importance to teach foreign language students the ability to understand and correctly render phraseological units of the target language. As is known, the structure of the English language differs from the structure of the Uzbek language and from the genetic point of view they belong to different language families. As a consequence, the grammatical structure of these languages also differs from each other. For example, in Uzbek there are a lot of affixes, a sentence begins with a noun and ends with a verb, there are no prepositions, no articles, no gender. And in English, on the contrary, there are articles, prepositions, and affixes are not developed. Therefore, when studying and interpreting words, word combinations, sentences, and especially phraseological units there are certain difficulties. The phraseological unit is an immutable, indivisible, from the point of view of the lexical structure, an integral combination of words, which performs the function of a single lexeme. The main features of phraseological units include semantic integrity, reproducibility of the phraseological unit, and disintegration of the structure. Every linguist, faced with the task of interpreting idioms, often finds it difficult to choose the method of interpretation of phraseological units. As a rule, phraseological units are rendered by phraseology, but this is not always possible, so in each case it is necessary to use different methods.

According to the researcher's point of view, phraseological units are divided into phraseological units that have equivalents in the target language, and non-equivalent phraseological units.

Equivalents can be full and partial equivalents. Full equivalents are equivalents that coincide with the phraseological units in the source language by meaning, lexical composition, imagery, stylistic orientation and grammatical structure. Such units include phraseological units of international character, based on mythological legends, historical facts and phraseological units of biblical origin. A partial equivalent, while conveying the meaning, contains lexical, grammatical or lexico-grammatical discrepancies. Therefore, we can say that a partial equivalent is equal to a full equivalent in the degree of adequacy of interpretation.

With the help of equivalents is rendered international phraseology, which includes phraseological units that entered into different languages from historical sources, mythology, borrowed from language to language, or originated in different peoples independently of one another due to the commonality of human thinking, proximity of certain aspects of social life of different peoples, their work activities.

Phraseological units are informative units, which reflect the perceptions and emotional attitude of a person to the surrounding reality. This statement is true, because "human life, comprehended in the categories of 
social consciousness, is recorded, interpreted and generalized in the categories of linguistic consciousness, which are verbalized by the system of lexical-phraseological means"

\section{RESULT}

It should be noted that phraseological units are considered to be the most difficult to be rendered as a lexical category, which can be explained by a number of reasons.

Firstly, by becoming components of a phraseological category, words with a free meanings lose their semantics and acquire a new, related meaning. For this reason, it is not enough to render phraseological expressions simply to select a dictionary correspondence for each component.

Secondly, a translator who is unfamiliar with the phraseology of the source language may find it difficult to recognize the phrase in the text of the interpretation, which will lead to a word-for-word or literalist interpretation, which in turn leads to distortion of meaning and the subsequent wrong perception of the information the target audience. Here it is also worth noting that a linguist who is not well versed in the phraseology of the who does not know the phraseology of the interpreting language, is also inevitably difficulties will inevitably arise. They will be associated with finding an equivalent of the original phraseology in the interpreting language or selection of an analogue.

Thirdly, sometimes even if there is an equivalent phraseology in the target language the interpreter needs to look for other ways of transferring meaning due to the fact that this phraseology does not fit the context. In this connection it is also worth taking into account that similar phrases in English and Uzbek languages can have different evaluative connotations.

Phraseological units are a special part of the lexical system of any language, the main linguistic guardians of the wisdom and culture of the people. Each phraseological unit has a figurative-expressive character and carries in itself a large amount of information. Phraseological units can be called a kind of "micro texts", absorbing a variety of information about what is happening. Phraseological units name the objects of reality, as well as transmit information, preserving the internal state of the speaker and his emotional attitude to the subject of speech (A.V. Kunin).

Phraseological phrases are the most important stylistic means in a work of fiction, providing expressiveness and beauty of form. The imagery of phraseology must be preserved in the interpretation - a text devoid of expression turns out standard and boring, and it can hardly be considered a full-fledged representative of the original. This is not an easy task - because the phraseological fund of each language is unique, it largely determines the linguistic specificity and flavor.

More importantly, the mutual difference between the form and meaning of English and Uzbek phraseological units generates difficulties in their interpretation. Although, if you think logically, you can find some similarities, associative variants, but when students hear English phraseological units for the first time, they accept only their form, without fully penetrating into their meaning or content. For example, "hot under the collar" is literally rendered into Uzbek as "yoqa ostidagi issiqlik" (hot under the collar), whereas the equivalent of this phraseological unit in Uzbek is "tepa sochi tikka bo'lmoq" (hair stood on end). As we can see from the example, the difference in form and in meaning is a difficulty in assimilation of phraseological units.

The majority of scholars are of the opinion that phraseological units possess a set of the following characteristic features: stability of the composition and structure of phraseological units, reproducibility of phraseological units in speech, integrity of semantics, impenetrability of structure, imagery.

When interpreting idioms, it is necessary to take into account the style of the original text, since the inappropriate use of idioms in a particular context can distort the meaning of the original and lead to an undesirable effect on the listener or reader. In addition, it is necessary to be able to distinguish a phraseological expression from a free phrase, pay special attention to the context, take into account the national coloring of the phraseological expression and try to create the most equivalent version of the interpretation for the unit of the source language. It is important to take into account the addressee for whom the interpretation is made.

One of the problems of interpretation of phraseology in modern prose is the fact that the composition of phraseology changes and develops, which aggravates the problem of identifying phraseological units in the original text and, accordingly, complicates the interpretation.

Phraseological expressions can contribute to a deeper and fuller understanding and comprehension of the work due to their richness, depth, imagery, as well as the ability to encapsulate the fullness of colors and emotions of the language of any nation.

Some of the phraseological expressions came into English through the American language. Most of the phraseological expressions of American origin came into English through American fiction. English idioms also include phrases borrowed from French, Spanish, Italian, German, Arabic, and Chinese. Some of the borrowed idioms, slightly modified into a more modern form, entered the vocabulary of the English language. All these idioms serve to enrich the English language. 


\section{CONCLUSION}

In the light of the foregoing, we can conclude that the interpretation of English phraseological expressions into Uzbek language is a difficult and responsible task. The difficulties faced by the translator stem from the differences in the vocabulary and grammatical structure of the two languages. In order to achieve the most accurate adequate interpretation of English phraseological expressions into Uzbek language, the linguist must use several methods of interpretation. Interpretation of idioms, proverbs and sayings can rightly be considered one of the most difficult aspects of interpretation. Because it is very difficult to render what is considered to be the spiritual heritage of the people, part of their culture. The meaning that one person understands seems to be something new to another. Often, in order to reveal the full meaning of a phraseology, one must find its equivalent in the target language. However, the actual process is not just a search for equivalent linguistic correspondences, but a complex, multifaceted process that, in addition to the skill and professionalism of the translator, is influenced by many other factors that subsequently affect the quality of the interpretation.

\section{References}

1. Kunin A.V. English-Russian phraseological dictionary. 4th edition. Русский язык. Moscow. 1984, 944 p.

2. Ginzburg R.S. A course in Modern English Lexicology. Moscow, 1979, 256 p.

3. Kuznetsova. A.M. Structural and semantic parameters in vocabulary. M .: 1980, $217 \mathrm{p}$. 